\title{
A HORTA ESCOLAR AGROECOLÓGICA NA EDUCAÇÃO AMBIENTAL E ALIMENTAR NO COLEGIO MILITAR TIRADENTES
}

\section{THE AGROECOLOGICAL SCHOOL HORTA IN ENVIRONMENTAL AND FOOD EDUCATION IN THE COLLEGE MILITARY TIRADENTES}

\begin{abstract}
Ana Caroline Oliveira Rodrigues ${ }^{1}$; Lariza Rayane Pinho Ferreira²; Kira Figueredo Alves³; Ana Julia Logrado da Conceição ${ }^{4}$; Msc. Denise Lima Cavalcante Marinho ${ }^{5}$.
\end{abstract}

DOI: https://doi.org/10.31692/978-65-991061-7-0.334-338

\section{INTRODUÇÃO}

Segundo Programa Nacional de Educação Ambiental - ProNEA (BRASIL, 1999), a educação ambiental é considerada um mecanismo para encarar os problemas ambientais na dimensão da educação, capaz de contribuir com mudanças e transformações sociais e envolver os diversos sistemas sociais. Assim, a educação ambiental requer uma articulação que promova ações voltadas à proteção, recuperação e melhorias socioambiental com efeito multiplicador na sociedade.

A implantação da horta escolar de base agroecológica visou promover o entendimento dos alunos a respeito uma agricultura saudável e realizar um alerta para o perigo na utilização dos agrotóxicos à saúde humana, dos animais e do ambiente. Para Crivellaro (2010), a agroecologia poder ser considerada como uma agricultura saudável que estimula as mudanças de modo de vida, de hábitos alimentares e padrões de consumo. Além disso, afirma que a nossa relação com a terra e com o uso sem controle dos recursos naturais só poderá ser modificada pelo processo educacional, com base na informação e formação individual e coletiva

A compostagem é uma prática agroecológica que no consiste no reaproveitamento do lixo orgânico na produção de adubo orgânico. Da mistura de restos de alimentos, frutos, folhas, estercos, palhadas, papel, papelão, etc, obtêm-se, no final do processo, um adubo homogêneo, sem cheiro, de cor escura, estável, solto, pronto para ser usado em qualquer cultura sem causar dano e proporcionando uma melhoria nas propriedades físicas, químicas e biológicas do solo (SOUZA et al., 2001).

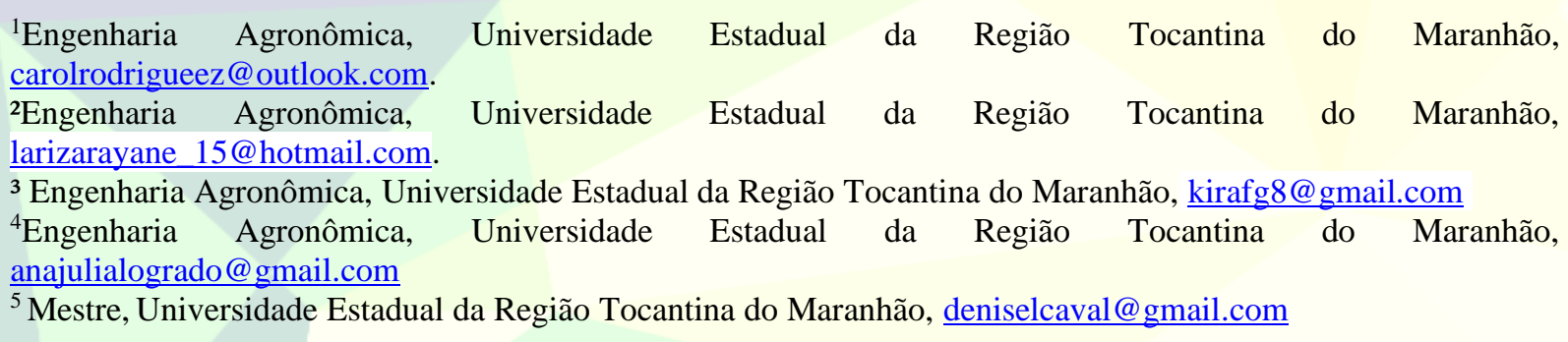


O aproveitamento dos resíduos orgânicos pode ser realizado no ambiente escolar através da implementação da coleta seletiva visando a reutilização do lixo orgânico para realizar o processo da compostagem, além oportunizar os alunos a aprender aproveitar lixo orgânico e promover a redução do lixo urbano.

Diante disso, este projeto visou a implantação de hortas agroecológicas no Colégio Militar Tiradentes II como meio para promover mudanças na aprendizagem e na conscientização alimentar e socioambiental.

\section{FUNDAMENTAÇÃO TEÓRICA}

O trabalho com horta escolar possibilita o desenvolvimento de diversas atividades pedagógicas em educação ambiental e alimentar, por meio de uma pequena produção de alimentos agroecológicos, unindo teoria e prática de forma contextualizada, auxiliando no processo de ensino-aprendizagem e estreitando relações através da promoção do trabalho coletivo e cooperativo entre os agentes sociais envolvidos (MORGADO, 2008), além disso, a horta escolar possibilita a construção de hábitos alimentares saudáveis e a redução dos custos referentes à merenda escolar.

Para Cobelo (2004), a educação ambiental é uma ferramenta de inclusão de saberes e disseminação de novos valores e serem apreendidos na consolidação de uma nova racionalidade. Nesse contexto a escola tem um papel fundamental na promoção de uma sociedade mais sustentável, uma vez que possibilita o trabalho em equipe, a socialização, a convivência com as diferenças, lidar com opiniões diversas, além de promover o desenvolvimento de habilidades no processo aprendizagem.

O processo educacional possibilita a formação de pessoas responsáveis e críticas, capaz de discutir questões associadas ao ambiente e sociedade e retomar suas relações com meio em que está inserido. Crivellaro (2010), afirma que o respeito à natureza é o ponto central dessa mudança, princípio básico da educação ambiental, a qual integra e sensibiliza para que os diversos segmentos da sociedade aliem seus esforços e canalizem suas energias para que a agroecologia aconteça através de vários métodos e práticas que alicerçam essa mudança.

\section{METODOLOGIA}

O projeto foi executado no Colégio Militar Tiradentes II - CMT, localizado na cidade de Imperatriz, Maranhão, com alunos do $6^{\circ}$ ao $9^{\circ}$ ano do ensino fundamental, no turno matutino. A natureza do trabalho é qualitativa. Inicialmente, foram realizadas palestras com 
alunos e professores para a exposição da parte teórica relacionado a produção agroecológica e metodologia de implantação do projeto.

Posteriormente foram distribuídas no prédio da escola lixeiras ornamentadas por alunos do $6^{\circ}$ e $7^{\circ}$ ano (Figura 1). As mesmas serviram para a separação dos resíduos orgânicos, visando a coleta de material para iniciar o processo da compostagem.

Figura 1 - Aluna do Colégio Militar Tiradentes II ornamentando lixeira de resíduos orgânicos, acompanhada

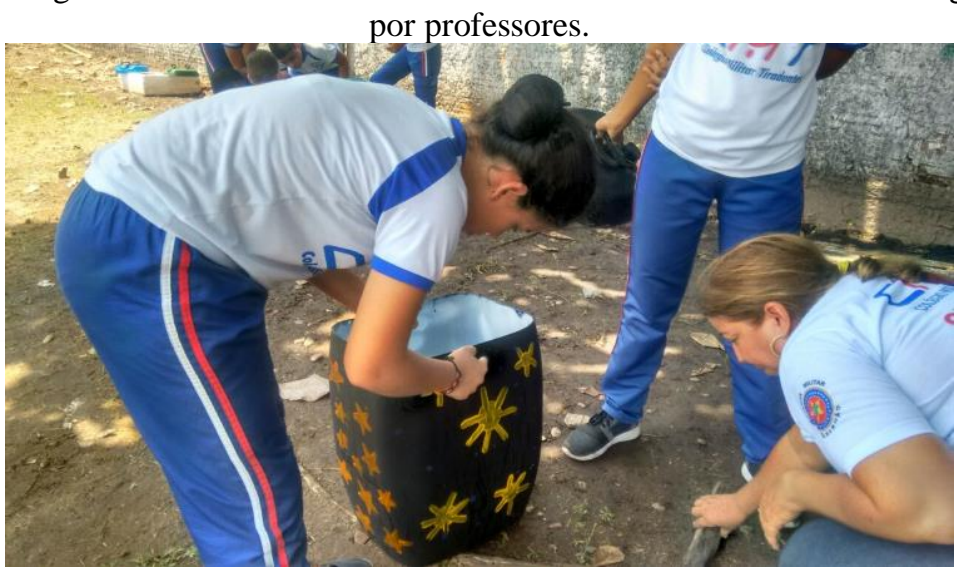

Fonte: Autor (2018).

Com o auxílio do Centro Acadêmico estruturou-se um rodizio de pessoal da comunidade escolar para o recolhimento do lixo orgânico e da manutenção da compostagem, tal como o dimensionamento dos canteiros, as espécies a serem plantadas e o método de regar manual. Foram distribuídos panfletos com informações detalhadas acerca do passo-a-passo da execução das etapas.

Inicialmente foi construída uma composteira com as dimensões de $4 \mathrm{~m} \mathrm{x} \mathrm{1,5} \mathrm{m} \mathrm{x} \mathrm{1,2} \mathrm{m,}$ montada a partir do lixo orgânico e de esterco doado por voluntários do projeto. Posteriormente, professores e alunos construíram seis canteiros, com o dimensionamento de $1,2 \mathrm{~m} \mathrm{x} 4 \mathrm{~m}$ x 0,3 m delimitados com garrafas PET adquiridas através de arrecadação (Figura 2). A primeira espécie cultivada foi alface, irrigada manualmente e utilizada na cozinha do colégio. Todos os conteúdos relacionados foram abordados em sala de aula.

Figura 2. Alunos do Colégio Militar Tiradentes II, construção de canteiros.

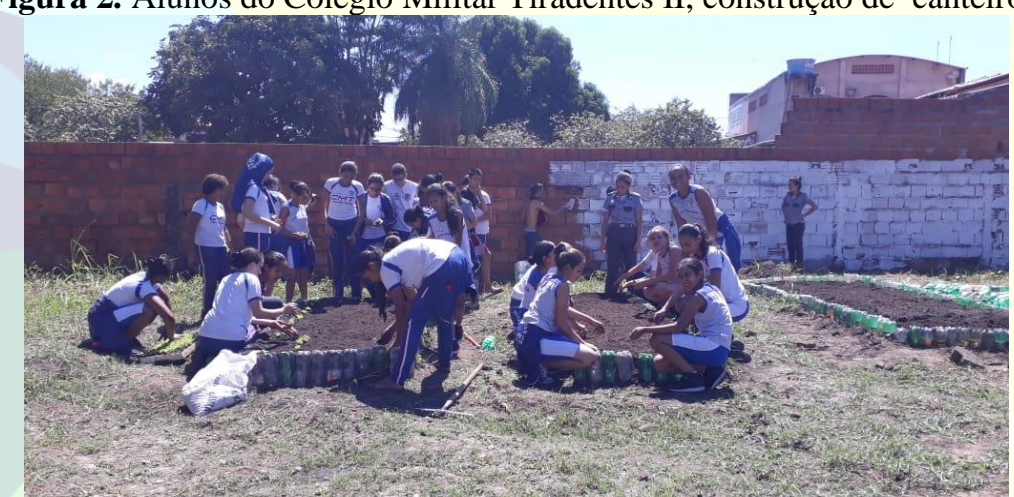

Fonte: Autor (2018). 
Figura 3 - Alunos do Colégio Militar Tiradentes II, plantio de mudas de alface e construção de canteiros.

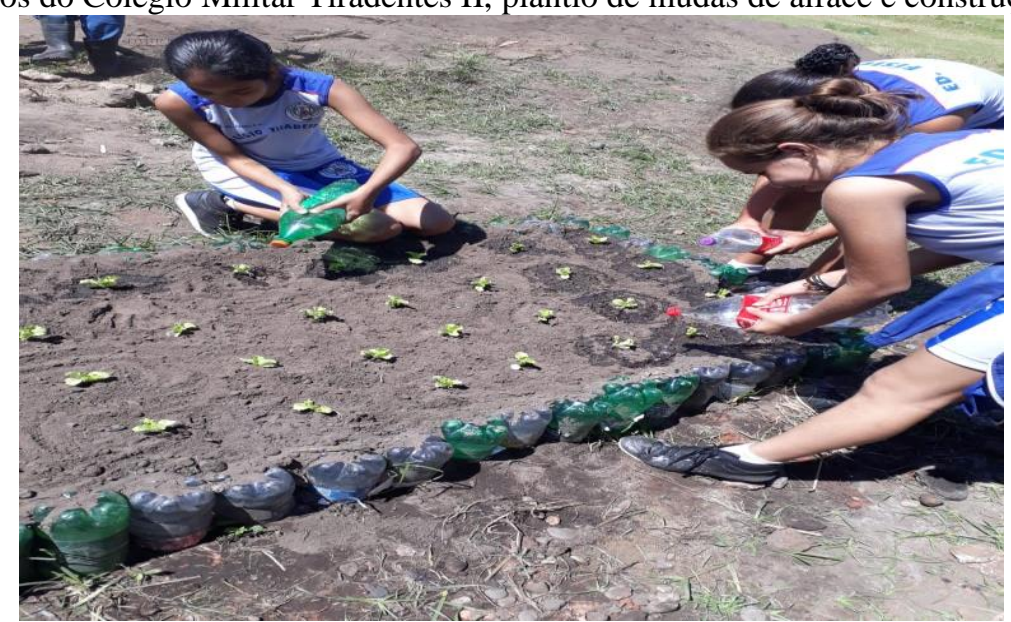

Fonte: Autor (2018).

\section{RESULTADOS E DISCUSSÕES}

Inicialmente houve atraso no cronograma do projeto devido às férias escolares de dezembro e janeiro. No entanto, a partir de março, todas as atividades desenvolveram-se com êxito, à exceção das compostagens, cuja necessidade de decomposição dos resíduos é extensa e não ficaram prontas para utilização até o término de vigência da bolsa.

Nessa perspectiva, os conteúdos foram apresentados por professores em sala de aula, atingindo os objetivos de interdisciplinaridade e propagação do conhecimento acerca da boa alimentação e práticas agroecológicas e sustentáveis.

A etapa mais difícil do projeto foi a confecção do rodízio devido a confluência de horários e o elevado número de turmas a se trabalhar. Além disso, a disponibilidade de professores acontecia geralmente às quintas-feiras e aos sábados, retardando a agilidade das atividades. No entanto, o colégio se mostrou extremamente comprometido com a importância dos conteúdos levantados e essa responsabilidade respaldou os objetivos, sendo alcançados com êxitos.

Os alunos participantes demostraram elevada competência na execução das atividades da horta, providenciando mudas, garrafas PET's, separando o lixo e comparecendo em dias pré-estabelecidos de montagem dos canteiros e compostagem

\section{CONCLUSÕES}

Durante o período de vigência da bolsa, o projeto visou a implementação de técnicas agroecológicas no CMT II e resultou na propagação de conhecimento alimentar e ambiental, disseminado por professores e alunos. Para aprimoramento e integração à grade escolar do colégio, no entanto, é necessário que haja continuidade das atividades, que são revertidas em 
alimentação e informação.

Nessa perspectiva, sendo os objetivos mantidos e a rotina de trabalho adequada de acordo com as alterações ocorridas gradualmente no colégio, a continuidade das atividades serão integradas de forma cada vez mais eficaz, influenciando o comportamento dos alunos e da comunidade envolvida.

Conclui-se que o trabalho foi de suma importância, alcançando os objetivos propostos inicialmente e apresenta excelentes perspectivas futuras.

\section{REFERÊNCIAS}

BRASIL, Ministério do Meio Ambiente e Ministério da Educação. Programa Nacional de Educação Ambiental. MMA/MEC, 1999.

COBELO, A.W. O papel da família no comportamento alimentar e nos transtornos alimentares. In: PHILIPPI, S.T.; ALVARENGA, M. Transtornos alimentares. São Paulo: Manole, 2004. p.119-130.

CRIVELLARO, Valeria Leonini et al. Agroecologia: um caminho amigável de conservação da natureza e valorização da vida. Núcleo de Educação e Monitoramento AmbientalNEMA. Rio Grande: NEMA, 2010

MORGADO, Fernanda da Silva. A horta escolar na educação ambiental e alimentar: experiência do Projeto Horta Viva nas escolas municipais de Florianópolis. 2008. 45p.

SOUZA, F. A; AQUINO, A. M; FEIDEN, A. Comunicado técnico. CT/50, Embrapa Agrobiologia, dez./2001, p.2. 